\title{
AVALIAÇÃO DA QUALIDADE DE SUCO DE LARANJA INDUSTRIALIZADO
}

\author{
VERA LÚCIA ARROXELAS GALVÃO DE LIMA * \\ ENAYDE DE ALMEIDA MÉLO * \\ LUECI DOS SANTOS LIMA **
}

Avaliou-se a qualidade do suco de laranja pasteurizado exposto à comercialização. Amostras refrigeradas e envasadas em embalagens "TetraPak", coletadas ao acaso, foram adquiridas no mercado varejista da cidade do Recife, durante o período de Setembro/98 a Julho/99. Foram avaliadas 03 marcas comerciais denominadas $A, B$ e C, perfazendo 60 amostras. Para cada marca comercial, as amostras foram adquiridas em duplicata, sendo uma destinada às análises físicoquímicas (vitamina " $\mathrm{C}$ ", acidez total titulável, sólidos solúveis totais e $\mathrm{pH}$ ) e a outra ao teste de incubação (35 ㄷ durante 10 dias). As marcas analisadas atenderam ao padrão de qualidade estabelecido pelo Ministério da Agricultura, exceto a marca C. Esta apresentou em $70 \%$ das amostras analisadas, teor de sólidos solúveis totais (SST) inferior ao padrão e sinais de deterioração durante o teste de incubação em $10 \%$ das amostras, evidenciando falhas no processamento térmico. O processamento asséptico associado ao armazenamento sob refrigeração permitiu que todas as amostras das marcas analisadas apresentassem quantidades de vitamina " $C$ " acima do valor mínimo estabelecido pelo Ministério da Agricultura.

\section{INTRODUÇÃO}

No Brasil, pela facilidade de obtenção de suco de laranja "fresco", a expansão do suco industrializado apresentava-se limitada, por ser o suco "fresco" o parâmetro de comparação (9). Entretanto, em busca de maior praticidade na vida atual, o mercado consumidor tem demonstrado

* Professora, Universidade Federal Rural de Pernambuco (UFRPE), Recife - PE (e-mail: vera@nelore.npde.ufrpe.br).

** Bolsista, Programa Institucional de Bolsas de Iniciação Científica - CNPq, UFRPE, Recife, PE. 
interesse em consumir cada vez mais os produtos "prontos para consumo". Dentro desta perspectiva surgiram diversas marcas comerciais de suco de laranja pasteurizado. Segundo o Ministério da Agricultura (4) este produto é definido como "o líquido límpido ou turvo extraído de laranja (Citrus sinensis (L) Osbeck) através de processo tecnológico adequado, não fermentado, de cor, aroma e sabor característicos, submetido a tratamento que assegure a sua apresentação e conservação até o momento do consumo".

O Brasil é um dos maiores produtores e exportadores do suco de laranja e a Comunidade Econômica Européia, sua principal compradora, adquiriu na safra de 94/95, 62\% das exportações brasileiras. Para o ano 2.000 existe a perspectiva de aumento na produção mundial de laranja e a concorrência internacional levará a agroindústria brasileira em busca de novos mercados nas regiões européia e asiática de modo a consolidar a imagem do suco brasileiro. Por outro lado, existem novas perspectivas com relação ao crescimento do mercado interno em função da mudança de hábito do povo brasileiro, que no início da década de 90 passou a consumir mais o suco pronto (2).

A industrialização de produtos alimentícios visa a obtenção de produtos com características sensoriais e nutricionais próximas ao produto in natura e que sejam seguros sob o ponto de vista microbiológico. É fundamental que estes produtos apresentem qualidade, visando não apenas atender aos padrões estabelecidos pela Legislação Brasileira mas, também, às exigências do mercado consumidor. Nas operações de processamento e durante o armazenamento de suco de frutas ocorrem transformações, que podem resultar em perdas no sabor e/ou aparecimento de sabor desagradável ("off flavor"), devido à várias reações bioquímicas complexas entre seus constituintes. Entretanto, com o avanço tecnológico, muitos alimentos vêm sendo conservados com o mínimo de alterações possíveis em suas características organolépticas e nutritivas, mediante processamento asséptico. Neste processamento, o produto é aquecido, resfriado e transportado sob condições estéreis aos recipientes, previamente esterilizados, sendo então hermeticamente fechados (9).

O processamento asséptico de suco de frutas alcançou rápido desenvolvimento, desde que a Food and Drug Administration (FDA) aprovou, em 1981, a utilização de peróxido de hidrogênio como agente esterilizante para embalagens contendo polietileno em sua parte interna (10). Quando comparado ao enchimento à quente ("hot fill"), os produtos obtidos pelo processamento asséptico apresentam melhor sabor, textura e cor, além de propiciarem menores perdas no valor nutritivo e mudanças nos componentes sensíveis ao calor (12).

GRAUMILICH, MARCY \& ADAMS (10) numa revisão sobre a influência das condições do processamento e embalagem na qualidade de suco de 
laranja, afirmaram que o processamento asséptico produz suco de melhor qualidade do que os processados pelo enchimento à quente. Entretanto, esta diferença pode desaparecer durante 0 armazenamento em temperatura ambiente, demonstrando que a temperatura de armazenamento é o principal fator para determinar a vida de prateleira de suco de laranja conservado por processamento asséptico.

Os sucos de frutas, cujo pH encontra-se na faixa de 2,0 a 4,5, apresentam condições favoráveis ao desenvolvimento de bolores, leveduras e bactérias ácido-tolerantes (16). Desta forma, tratamento térmico na faixa de $85{ }^{\circ} \mathrm{C}$ $95{ }^{\circ} \mathrm{C}$, durante 15 a 20 segundos, é apropriado para tornar o produto comercialmente estéril, tendo em vista que é suficiente para a destruição destes microrganismos e a inativação de enzimas capazes de promover transformações indesejáveis que possam comprometer a qualidade do produto (9). O alimento comercialmente estéril, embora possa conter número reduzido de microrganismos e esporos viáveis que não serão capazes de se desenvolver, apresenta vida de prateleira prolongada, sendo seguro à saúde do consumidor (3).

O Ministério da Agricultura estabelece que o suco de laranja industrializado deve conter no mínimo $38 \mathrm{mg} \%$ de ácido ascórbico (4). Assim, o processamento deve minimizar ao máximo as reações que concorrem para diminuição do valor nutritivo e de outros atributos de qualidade do produto. CARVALHO e GUERRA $(6,7)$ pesquisaram o efeito do tratamento térmico sobre as características físico-químicas e microbiológicas do suco de acerola pasteurizado, bem como sua estabilidade durante 0 armazenamento. A temperatura de $70 \stackrel{\circ}{\circ}$ por 15 minutos, usada na pasteurização, foi suficiente para assegurar estabilidade microbiológica ao produto, sem alteração na cor, no $\mathrm{pH}$ e com perdas mínimas do teor de ácido ascórbico. No entanto, ao armazenar o suco durante 150 dias, a temperatura ambiente $\left(28{ }^{\circ} \mathrm{C} \pm 2\right.$ ), foi observado que houve perda de ácido ascórbico da ordem de $33,8 \%$ e redução no teor de polpa suspensa. Sucos frescos de laranja, não pasteurizados e envasados em garrafas de vidro assépticas, foram estudados por RUSSO e BONAVENTURA (14). Os sucos armazenados a $7 \stackrel{\circ}{\circ} \mathrm{C},{ }^{\circ} \mathrm{C}$ e $1 \stackrel{\circ}{\circ} \mathrm{C}$ mantiveram boa qualidade durante oito a vinte e um dias, vinte e um a quarenta e dois dias e vinte e quatro a cinqüenta dias, respectivamente. Tais pesquisadores constataram também que não houve alteração significativa nas propriedades físico-químicas do suco, apenas redução de 15\% no teor de ácido ascórbico, após 20 dias de armazenamento.

Diante do crescente consumo do suco de laranja industrializado e do surgimento de diversas marcas comerciais pretendeu-se, neste estudo, avaliar a qualidade deste produto exposto à comercialização na cidade do Recife - PE. 


\section{MATERIAL E MÉTODOS}

Sucos de laranja pasteurizados e refrigerados, envasados em embalagens "Tetra-Pak", coletados ao acaso, foram adquiridos mensalmente no mercado varejista da cidade do Recife, durante o período setembro/98 a julho/99. Foram avaliadas três diferentes marcas comerciais que receberam para identificação as letras $\mathrm{A}, \mathrm{B}$ e $\mathrm{C}$. As marcas comerciais $\mathrm{A} e$ $C$ referem-se ao suco de laranja obtido de frutas frescas, enquanto que a marca B ao suco de laranja reconstituído a partir de suco concentrado. Para cada marca comercial, as amostras foram adquiridas em duplicata, sendo uma destinada às análises físico-químicas e a outra, ao teste de incubação. Durante o período estudado foram analisadas vinte amostras das diferentes marcas comerciais e de diferentes lotes, num total de sessenta amostras, estando todas enquadradas no prazo de validade estabelecido pela indústria processadora.

As amostras foram mantidas sob refrigeração até próximo ao término do prazo de validade, quando foram determinados os sólidos solúveis totais (SST), pH e acidez total titulável (ATT), segundo metodologia descrita pela AOAC (1), teor de vitamina "C" total pelo método espectrofotométrico, utilizando 2,4- dinitrofenilhidrazina (15), teste de incubação a $35 \stackrel{\circ}{ } \mathrm{C}$, por 10 dias (5) e a relação SST/ATT determinada pelo quociente entre os dois constituintes.

\section{RESULTADOS E DISCUSSÃO}

Os produtos estudados apresentaram sabor e aroma próprios de laranja. As características físico-químicas dos sucos estudados encontram-se nas Tabelas 1,2 e 3 . Observou-se que as marcas A e B atenderam aos padrões de qualidade e identidade determinados pelo Ministério da Agricultura (Portaria № 371), que estabelece para o suco de laranja integral industrializado os seguintes limites: ácido ascórbico, mínimo de $38 \mathrm{mg} / \%$; SST, mínimo de 10,5 Brix e SST/ATT na faixa de 9,0 a 20,0. Entretanto, $70 \%$ das amostras da marca $C$ apresentaram teor de SST na faixa de 9,6 a 10,2ํㅡㄹ Brix e portanto, abaixo dos limites mínimos fixados pelo Ministério da Agricultura (MA).

Em todas as amostras das marcas analisadas, a quantidade de vitamina "C" encontrada foi superior ao limite mínimo estabelecido pelo MA. Verificou-se que o produto industrializado, mantido sob refrigeração, por até 4 semanas (vida de prateleira determinada por todos os produtores), fornece quantidade apreciável de vitamina "C". NAGY (13) afirmou que a perda de vitamina " $\mathrm{C}$ " em produtos cítricos é causada principalmente pela incorporação de ar durante as etapas de processamento que favorece as reações aeróbicas de degradação, além da temperatura e tempo de 
armazenamento, sendo o uso de baixas temperaturas, condição imperativa para a retenção de vitamina "C" durante a estocagem. Portanto, sucos simples ("single-strength") e reconstituídos podem ser armazenados sob refrigeração por 4 semanas sem sérias perdas de vitamina " $C$ ". MANNHEIM \& HAVKIN (12) estudaram a estabilidade de suco de laranja conservado pelos processos de enchimento à quente ("hot fill") e enchimento asséptico, ambos envasados em garrafas de vidro. Verificaram que os sucos conservados pelo processo asséptico e armazenados a $15 \mathrm{e}$ $25 \stackrel{\circ}{\circ}$ apresentaram melhor retenção de ácido ascórbico do que os sucos conservados pelo processo de enchimento à quente e armazenados a mesma temperatura. Entretanto, quando os dois tipos de suco foram armazenados a $4 \stackrel{\circ}{\circ}$, além de não apresentarem diferença na perda de ácido ascórbico, o conteúdo desta vitamina para ambos os sucos decresceu cerca de 5\%, após 70 dias de armazenamento. Afirmaram, portanto, que o principal fator na estabilidade da vida de prateleira ("shelflife") não foi o método de enchimento e sim, a temperatura de armazenamento.

TABELA 1 - CARACTERÍSTICAS FÍSICO-QUÍMICAS DE SUCO DE LARANJA DA MARCA "A"

\begin{tabular}{cccc}
\hline \multicolumn{3}{c}{ Determinações } \\
\hline Amostras & $\begin{array}{c}\text { Vitamina C } \\
\text { mg/100 g }\end{array}$ & $\begin{array}{c}\text { SST } \\
\left({ }^{\circ} \text { Brix }\right)\end{array}$ & SST/ATT \\
\hline 1 & 45,68 & 10,8 & 12,86 \\
2 & 48,52 & 10,8 & 12,86 \\
3 & 44,96 & 10,8 & 12,86 \\
4 & 47,28 & 10,8 & 12,86 \\
5 & 53,98 & 10,8 & 12,86 \\
6 & 46,56 & 10,6 & 15,14 \\
7 & 46,56 & 10,8 & 12,86 \\
8 & 45,25 & 10,6 & 12,62 \\
9 & 39,18 & 11,0 & 13,10 \\
10 & 38,81 & 10,6 & 12,62 \\
\hline
\end{tabular}

SST = Sólidos solúveis totais .

ATT = Acidez total titulável.

Os sucos de laranja utilizados neste estudo foram processados assepticamente e estavam acondicionados em embalagens "Tetra-Pak". A técnica de processamento asséptico associada ao armazenamento refrigerado permite manter a estabilidade e a qualidade de sucos cítricos (10). TOCCHINI et al. (17) avaliaram o efeito do processamento térmico de suco de laranja concentrado (50 Brix), envasado em latas e pasteurizado, processado assepticamente e embalado em "Tetra-brik". Evidenciaram que 
aos 30 dias de estocagem $\left(25^{\circ} \mathrm{C}\right.$ ), apesar do suco enlatado ter apresentado maior retenção de ácido ascórbico e menor escurecimento, o produto obtido pelo processo asséptico e embalado em "Tetra-brik" foi o preferido pelo painel de degustadores. Segundo GAVA (9) a embalagem "Tetra-Pak" garante a ausência de espaço livre e, conseqüentemente, a remoção considerável de oxigênio, reduz a oxidação da vitamina " $C$ ". Entretanto, pequenas quantidades de oxigênio dissolvido no produto são capazes de, em função da temperatura de armazenamento, proporcionar certas perdas de vitamina "C". Porém, este dano pode ser minimizado com o armazenamento do produto sob refrigeração. Outro benefício dos baixos níveis de oxigênio e da temperatura de armazenamento do produto (refrigeração) é prevenir o crescimento dos microrganismos sobreviventes ao processamento.

\section{TABELA 2 - CARACTERÍSTICAS FÍSICO-QUÍMICAS DE SUCO DE LARANJA DA MARCA "B"}

\begin{tabular}{cccc}
\hline \multicolumn{3}{c}{ Determinações } \\
\hline Amostras & $\begin{array}{c}\text { Vitamina C } \\
\text { mg/100 g }\end{array}$ & $\begin{array}{c}\text { SST } \\
\left({ }^{\circ} \text { Brix }\right)\end{array}$ & SST/ATT \\
\hline 1 & 55,32 & 10,8 & 12,86 \\
2 & 54,31 & 10,8 & 12,86 \\
3 & 51,33 & 10,8 & 12,86 \\
4 & 56,83 & 10,8 & 12,86 \\
5 & 57,12 & 11,0 & 13,10 \\
6 & 59,14 & 11,0 & 13,10 \\
7 & 48,15 & 10,8 & 12,86 \\
8 & 53,79 & 10,8 & 12,86 \\
9 & 58,85 & 11,0 & 13,10 \\
10 & 48,58 & 11,0 & 13,10 \\
\hline
\end{tabular}

SST = Sólidos solúveis totais.

ATT $=$ Acidez total titulável.

Sabe-se que o teor de vitamina $C$ em frutos varia em função de diversos fatores, como clima, estádio de maturação, condições de armazenamento e variedade entre outros (13). Entretanto, apesar de não se ter conhecimento dos valores de vitamina "C" nos sucos estudados antes do processamento, os resultados encontrados estão próximos ou superiores aos relatados por CEREDA, SALIBE e FERREIRA (8) para 10 diferentes 
cultivares de laranja doce, os quais variaram de 42,9 a 47, $1 \mathrm{mg} / 100 \mathrm{~g}$. Assim, o processamento asséptico, associado ao armazenamento do produto sob refrigeração, garante a ingestão de suco de laranja industrializado como fonte segura de vitamina " $\mathrm{C}$ ", colaborando para atender às necessidades diárias desta vitamina.

\section{TABELA 3 - CARACTERÍSTICAS FÍSICO-QUÍMICAS DE SUCO DE LARANJA DA MARCA "C"}

\begin{tabular}{cccc}
\hline \multicolumn{5}{c}{ Determinações } & \\
\hline Amostras & $\begin{array}{c}\text { Vitamina C } \\
\text { mg/100 g }\end{array}$ & $\begin{array}{c}\text { SST } \\
\left({ }^{\circ} \text { Brix }\right)\end{array}$ & SST/ATT \\
\hline 1 & 45,67 & 10,0 & 14,20 \\
2 & 48,52 & 10,8 & 12,86 \\
3 & 43,52 & 10,2 & 12,14 \\
4 & 46,99 & 10,8 & 15,43 \\
5 & 48,44 & 10,0 & 14,29 \\
6 & 49,16 & 10,0 & 14,29 \\
7 & 61,31 & 10,0 & 11,90 \\
8 & 47,14 & 9,6 & 9,80 \\
9 & 43,66 & 10,2 & 12,14 \\
10 & 39,18 & 10,6 & 10,82 \\
\hline
\end{tabular}

SST = Sólidos solúveis totais.

ATT = Acidez total titulável.

Os valores de $\mathrm{pH}$ encontrados nas amostras variaram de 3,6 a 3,9 (dados não apresentados). Segundo LEITÃO (11) o pH é o fator que exerce maior efeito seletivo sobre os microrganismos aptos a se desenvolverem. Assim, a microflora dos produtos ácidos é relativamente restrita, contendo microrganismos de menor resistência térmica, o que torna o processo de pasteurização suficiente para a conservação de suco de laranja.

A Portaria no 451 do Ministério da Saúde não estabelece padrões microbiológicos para refrigerantes, refrescos, sucos e néctares que receberam tratamento térmico adequado, adicionado ou não de conservadores. Determina que "após 10 dias de incubação a $35{ }^{\circ} \mathrm{C}$ não devem existir sinais de alteração das embalagens, nem quaisquer modificações físicas, químicas ou organolépticas do produto que evidenciem deterioração". Para avaliar as condições de processamento no que se refere à estabilidade do produto e ao fechamento hermético das embalagens, as amostras foram incubadas a $35{ }^{\circ} \mathrm{C}$ durante 10 dias. Os 
resultados obtidos demonstraram que as amostras, apesar de apresentarem coloração mais escura, quando comparadas às mantidas sob refrigeração, mantiveram odor agradável, característico de suco de laranja, com ausência de estufamento e produção de gás. Apenas uma amostra da marca C apresentou sinais de deterioração pela turvação do suco e presença de aroma desagradável, típico de processo fermentativo, indicando falhas no processamento térmico.

\title{
4 CONCLUSÃo
}

Os resultados obtidos permitem concluir que, todas as amostras das marcas analisadas apresentaram quantidade de vitamina "C" acima do valor mínimo estabelecido pelo Ministério da Agricultura. O suco de laranja da marca $C$ foi considerado de qualidade inferior quando comparado com as amostras das demais marcas estudadas.

\begin{abstract}
The quality of pasteurized orange juice exposed to commercialization was evaluated. Samples, refrigerated and packed in "Tetra-Pak" randomly collected were bought at the retail trade market of Recife, during the period of September/98 to July/99. Three commercial labels named $A, B$ and $C$ were evaluated, making a total of 60 samples. For each commercial label, the samples were acquired in two replicates, one of which was destined to physicochemical analysis (vitamin $\mathrm{C}$, total acidity, total soluble solids and $\mathrm{pH}$ ) and the other to the incubation test ( $35^{\circ} \mathrm{C}$ during 10 days). The labels assayed assisted to the established quality pattern of the Ministry of Agriculture, except the $C$ label. This label presented in $70 \%$ of the analyzed samples, lower TSS rates than those considered as standard, it also showed signs of deterioration during the incubation test in $10 \%$ of the samples, evidencing flaws in the thermal procedure. The aseptic procedure associated to the refrigerated storage allowed all samples of the assayed labels to show vitamin $C$ levels higher than the minimum established by the Ministry of Agriculture.
\end{abstract}

\section{REFERÊNCIAS BIBLIOGRÁFICAS}

1 ASSOCIATION OF OFFICIAL ANALYTICAL CHEMISTS. Official Methods of Analysis of the Association of Official Analytical Chemists. 15.ed. Virginia, 1990. v 1 e $v 2$.

2 BAHIA. Secretaria da Agricultura, Irrigação e Reforma Agrária. Frutas: a caminho de um grande mercado. Salvador, 1996. p 67-77.

3 BARUFFALDI, R., OLIVEIRA, M. N. de. Conservação de alimentos por tratamento térmico. In: Fundamentos de tecnologia de alimentos. São Paulo: Atheneu, 1998. v. 3, Cap. 5. 
4 BRASIL. Ministério da Agricultura. Portaria n. 371 de 19 de setembro de 1974. Complementa padrões de identidade e qualidade para suco de laranja. Diário Oficial [da República Federativa do Brasil], Brasíla, 19 de setembro de 1974.

5 BRASIL. Ministério da Saúde. Portaria n. 451 de 19 de setembro de 1997. Aprova o regulamento técnico de princípios gerais para o estabelecimento de critérios e padrões microbiológicos para alimentos. Diário Oficial [da República Federativa do Brasil], Brasília, 22 de setembro de 1997. p. 21005

6 CARVALHO, I.T. de, GUERRA, N.B. Efeito de diferentes tratamentos térmicos sobre às características do suco de acerola. In: SÃO JOSÉ, A R., ALVES, R.E. Acerola no Brasil: produção e mercado. Vitória da Conquista (BA) : DFZ/UESB, 1995. p. 96101.

7 Suco de acerola: estabilidade durante o armazenamento. In: SÃO JOSÉ, A R., ALVES, R.E. Acerola no Brasil : produção e mercado. Vitória da Conquista (BA) : DFZ/UESB, 1995. p. 102106.

8 CEREDA, E., SAliBE, A. A., FERREIRA, V. L. P. Caracterização de cultivares de laranja doce Citrus sinensis $(L)$ Osbeck de baixa acidez. In: CONGRESSO BRASILEIRO DE FRUTICULTURA, 7., Florianópolis, 1984. Anais ... Florianópolis, 1984. v. 2, p. 565575.

9 GAVA, A. J. Processamento asséptico de suco de frutas. Alimentação, v. 76, n. 1, p. 32-37, 1985.

10 GRAUMLICH, T. R., MARCY, J. E., ADAMS, J. P. Aseptically packaged orange juice and concentrate: a review of the influence of processing and packaging conditions on quality. Journal of Agriculture and Food Chemistry, v. 34, n. 3, p. 402-405, 1986.

11 LEITÃO, M.F.F. Microbiologia de sucos e produtos ácidos. Boletim do ITAL. Campinas, v. 33, p. 9-42, 1973.

12 MANNHEIM, C.H., HAVKIN, M. Shelf-life of aseptically bottled orange juice. Journal of Food Processing and Preservation, v. 5, p. 16, 1981.

13 NAGY, S. Vitamin C contents of citrus fruit and their products: a review. Journal of Food Processing and Preservation, v. 28, n. 1, p. 8-18, 1980. 
14 RUSSO, C., BONAVENTURA, S. Refrigeration of blood oranges destined to the transformation. Note 1: Tests on the juice stability. Industrie delle Bevande, v. 21, n. 122, p. 494-500, 1992.

15 STROHECKER, R., HENNING, H.M. Vitamin assay tested methods. Weinheim/Bergstr : Verlag Chemie, 1965. $360 \mathrm{p}$.

16 UBOLDI EIROA, M.N. Microrganismos deteriorantes de suco de frutas e medidas de controle. Boletim da Sociedade Brasileira de Ciência e Tecnologia de Alimentos, Campinas, v. 23, n. 3/4, p. 141-160, 1989.

17 TOCCHINI, R. P., MORI, E. E. M., FERREIRA, V. L. P., PASCHOALINO, J. E. Efeito do processamento térmico e do tipo de embalagem na qualidade do suco de laranja concentrado e pasteurizado. Boletim do ITAL. Campinas, v. 21, n. 1, p. 61-71, 1984. 